a sound basis for the aggregation or comparison of regional data. However, the Department of Health in conjunction with the National Forum on Drug Data has decided that implementation of the DMDs throughout the various regions is now consistent enough to warrant publication of the figures submitted for the six months ending 31 March 1993.

Data are currently collected from the majority of specialist drug units, both statutory and non-statutory, throughout the country. However, many drug users are seen within general psychiatric settings, and it is therefore vitally important to the validity of the DMDs that data are collected from general psychiatrists.

Within the general psychiatric unit, the volume of data to be collected will be less than within the specialist unit and therefore less time consuming. However, the fact that data need to be gathered only from those patients who misuse drugs means that the task is easily forgotten.

The form itself consists of one side of A4, with tick-boxes for most items: the majority of doctors who have had experience in completing the form agree that it takes around five minutes. A few regions provide software for data-entry and report-generation on site, while in the majority of regions these functions are performed centrally and specific reports generated on request to the database manager. The notification form also provides the means of meeting the doctors' obligation to notify the Home Office of those patients they consider to be dependent on a range of controlled drugs.
Data from the DMDs are already widely used. Most regional health authorities provide regular reports based on DMD statistics, as well as responding to requests for more specific information. An excerpt is available on request from a recent publication by the four Thames regional health authorities in which problem drug use in Greater London, as reported to the DMDs, was examined (Daniel et al, 1993). The report has been widely welcomed by service providers, purchasers and policy makers.

For further information about your regional drug misuse database, contact your regional drug misuse database manager who will normally be located within the regional health authority offices.

\section{References}

DANiEl, P., Brown, A., Jones, M. \& MORGAN, D. (1993) Problem Drug Use Reported by Services in Greater London: a collaborative report by the Regional Drug Misuse Databases. St George's Hospital Medical School, Tooting. London SW17 ORE.

Substance Abuse Assessment Questionnaire. In Drugs and Addictlve Behaviour: a guide to treatment. (A.H. Ghodse, 1989) Oxford: Blackwell Scientific.

Hamid Ghodse, Chairman, Substance Misuse Section, The Royal College of Psychiatrists; Megan Jones, Regional Database Manager, South West Thames Regional Health Authority; and Anthony Thorley, Senior Medical Officer, Alcohol and Drugs, Department of Health

\title{
A visit to Byelorus
}

\section{Robin Jacoby and Catherine Oppenheimer}

Byelorussia or Byelorus (ye pronounced as in B'yellow) means White Russia, metaphorically named as the only part of Russia never to have been conquered by the Tartars. One of the former Soviet republics, it lies sandwiched between Russia to the east and Poland to the west with the Baltic states to the north. To the south lies Ukraine with Chernobyl only a stone's throw from the border. This fact of geography allied to the prevailing wind resulted in more than $70 \%$ of the damage from the nuclear disaster falling to Byelorussia rather than Ukraine.
The population of Byelorussia is about 11 million, some two million of whom live in the capital, Minsk. Byelorussians were relatively more isolated from western contact and influence than their counterparts in Moscow, Leningrad and Kiev. With the collapse of the Soviet state they have been keen to make up for lost time and to establish links with other countries which will not only help them to recover from a disastrous economic situation but also to learn from ideas, medicine, social systems and legislation. It was in this spirit that Professor Vladimir Ivanov, 
Chief Psychiatrist at the Byelorussian Ministry of Health, made an approach to the Department of Health which resulted in our trip to Minsk in mid-October 1992 . We had been chosen as Russian-speaking psychiatrists. At the Department's request we included a nurse, Steve Corea from Oxford, who speaks no Russian but whose body language and warmth of personality proved that effective communication is not simply a matter of words.

Byelorussian psychiatric services are based on a few big regional mental hospitals and more widely dispersed municipal psychiatric hospitals, called 'dispensaires'. Within this system there are numerous lines of separation. Psychiatry is separate from addiction services. Child psychiatry is distinct from adult psychiatry right from the undergraduate level. The only connections between in-patient and out-patient services are the patients themselves and the documentation that accompanies them. On the other hand, neurology and neurosurgery are closer to psychiatry than in the UK and contribute to the more organic orientation of Byelorussian psychiatry. Psychiatric practice is very much hospital-based, although some embryonic community services exist: outreach nurses working with chronically ill patients at home, community day care for alcoholic patients and a 24-hour help-line manned by psychologists, for example.

A visit to the Republican Hospital, the big mental hospital for the Minsk region, offers a glimpse of our own past. The hospital contains thousands of patients, the majority in hospital clothes, with the staff all in white coats. The average ward has 70 patients and two nurses on duty at one time. A fairly strict hierarchy exists with nurses required only to carry out the instructions of doctors. The wards we saw were clean, warm and comfortable, and although they were institutional in style with little individual privacy, the atmosphere was friendly and informal.

We could not easily have predicted our colleague Steve's impact on our hosts. At first they were politely surprised at his inclusion in the party, but as time went on it began to dawn on them how important nurses are in our system as independent colleagues with their own body of expertise. At each hospital we visited Steve managed to get the senior nurse to take him away from us doctors so that he could talk to her (always her) nurses on their own. When they rejoined the party everyone was beaming and his Russian title became more and more honorific as our visit progressed.

The municipal hospitals or dispensaires have some in-patient beds. Formerly these beds were for less severe cases, while patients with major (usually psychotic) illnesses were referred on to the regional hospitals. Now new budgetary rules mean that such referrals are effectively ECRs, at the expense of the municipality, and the municipal hospitals are therefore under pressure to keep their severely ill patients, without the resources or the experience to look after them properly. It is in the dispensaires that the majority of the out-patient work occurs. Addiction services have their own dispensaires, alcohol abuse being a matter of epidemic proportions in the republics of the old USSR.

Many treatment methods are the same as ours, although the economic catastrophe has left them to some extent dependent on Western charity. principally German, for supplies of psychotropic drugs. Treatment differences were more interesting. Insulin coma therapy is still used but ECT is much less common. Indeed, we gained the impression that they consider ECT rather barbaric. However, their reasons for not giving it seem to be based mainly on a shortage of anaesthetic drugs. relaxants and skilled anaesthetists so that their view of ECT is based on the unmodified version.

The scarcity of modern drugs partly accounts for the considerable number of alternative therapies employed: exercise, swimming, hydrotherapy, relaxation, acupuncture, hypnotherapy, reflexology, neuro-linguistic programming, auriculotherapy and iridotherapy. In the Republican Hospital hyperbaric oxygen is used for depression, detoxification of addictive states and 'febrile schizophrenia'.

The traditional emphasis in clinical practice and training was on diagnosis and the prescription of physical treatments. The patients (especially those with neurotic illness) acted as willing recipients of these more or less magical treatments. Now, however, many academics and clinicians appreciate the need to learn more about the psychological methods of treatment (dynamic and others) in neurotic illness, in liaison psychiatry, in the addictions, and in giving a broader perspective to psychiatric practice as a whole. They are eager to establish there methods in their training programmes, and look to the West for advice and help in this.

One of the main items on the Byelorussian agenda for our visit was mental health legislation. There is currently a movement among reform-minded MPs, conscious of the abuses of the past, to protect civil liberties by a legally based system in which formal admission to hospital can take place only if sanctioned by a tribunal. The profession, on the other hand, is fearful of a cumbersome process in which nonpsychiatrists will, in effect, be making diagnostic decisions. They are anxious to introduce legislation which is similar to our own Mental Health Act (MHA) which they see as the best compromise between the protection of civil liberties and the patient's right to treatment. We were frequently called upon to explain the MHA and how it 


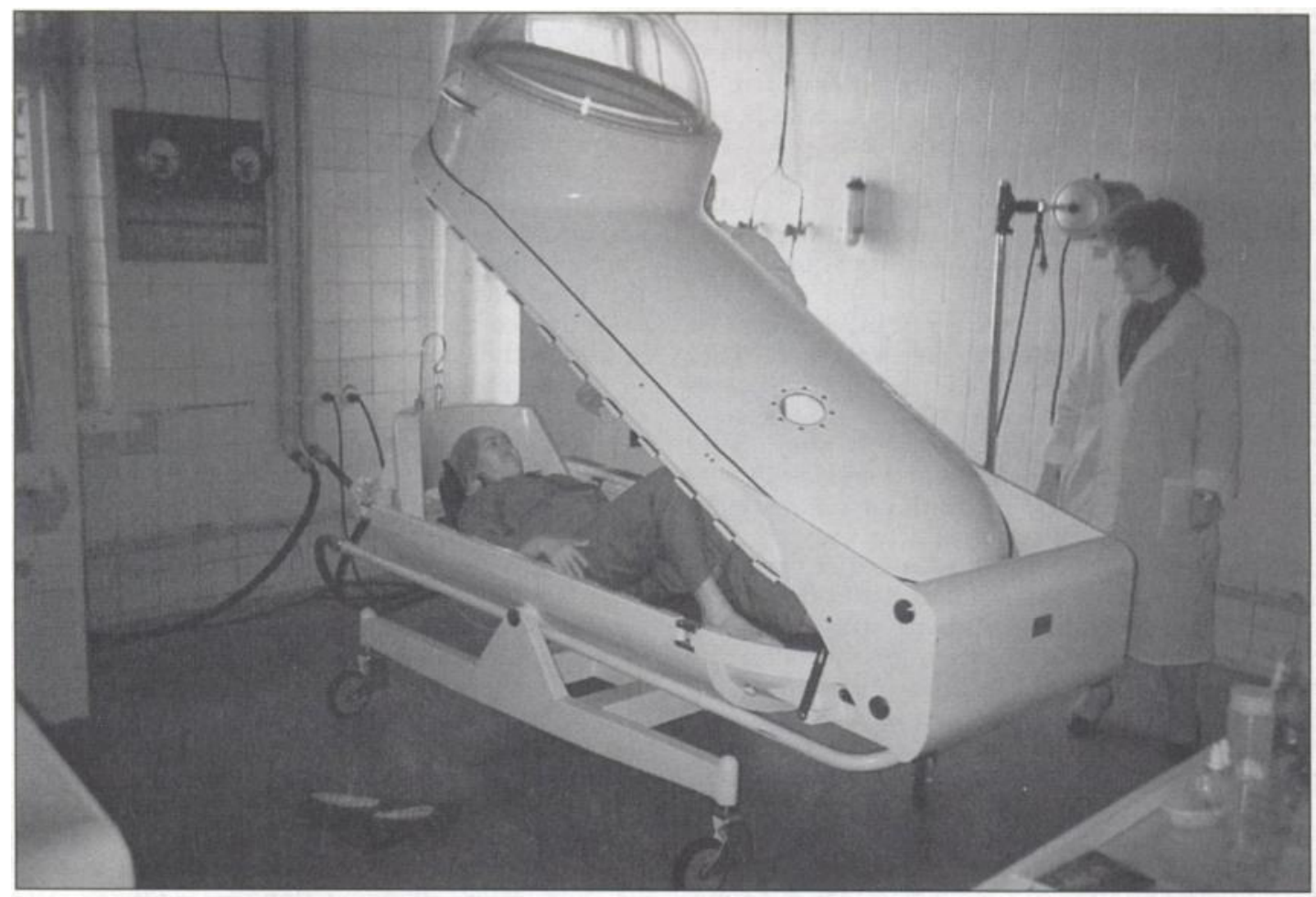

A depressed patient prepares for hyperbaric oxygen therapy.

works. At the Republican Hospital in front of the entire medical staff we chose to do this by role-playing the process of formal admission for assessment and detention for treatment, not forgetting, of course, the nurses' part.

We received the warmest hospitality in Minsk. There was an openness, a readiness to share their criticisms of their own practice, and an eagerness to learn that humbled us, knowing how far from perfect our own situation and practice are. In Byelorussia they have a system which is archaic and underfunded. By and large it is operated by intelligent, enthusiastic and talented people who are only too willing to acknowledge deficiencies. Insofar as the UK is concerned, they are not looking for money but for expertise in showing them how to help themselves. Most if not all of those in power are reform-minded. They would like to send two or three senior Englishspeaking psychiatrists over here for about a month to see how we run our services, how we teach undergraduates, how we train specialists, and how our mental health legislation operates.
We think they also need to learn multidisciplinary working and the research culture, in particular that which evaluates old treatments and new services developments. This is the moment in history when we can truly support the efforts of the excellent colleagues in a beleaguered and underdeveloped specialty. For many years the West, with the College in the vanguard, has been rightly critical of abuses of psychiatry in the Soviet Union. With the Union dissolved, and psychiatrists of the Republics searching for a better way forward, we are surely under obligation to help. At the time of going to press we are organising a visit to Britain for three senior Byelorussian psychiatrists. We look forward to sharing with them the expertise and goodwill of our colleagues, the readers of the Psychiatric Bulletin.

Robin Jacoby, Consultant Psychiatrist, The Maudsley Hospital, London SE5 8AZ; and Catherine Oppenheimer, Consultant Psychiatrist, The Warneford Hospital, Oxford OX3 7JX 